\title{
Structural Characteristics of Porous Silicon
}

\author{
Qadeer Hussain1, Arifullah1, Nazir A. Naz², Ammar Akbar ${ }^{3}$, Akbar Ali1,2 \\ ${ }^{1}$ Ripha International University, Islamabad, Pakistan \\ ${ }^{2}$ Fedral Urdu University of Arts, Science and Technology, Islamabad, Pakistan \\ ${ }^{3}$ Nikon, 6th Road Satllite Town, Rawalpindi, Pakistan \\ Email: aarandhawa@yahoo.com
}

Received 23 January 2014; revised 22 February 2014; accepted 21 March 2014

Copyright (C) 2014 by authors and Scientific Research Publishing Inc.

This work is licensed under the Creative Commons Attribution International License (CC BY). http://creativecommons.org/licenses/by/4.0/

(c) (i) Open Access

\begin{abstract}
Silicon wafers (p-type) were etched under continuous flow of HF vapors in a reaction chamber at standard temperature and pressure. Etched surface of the silicon wafer was found emitting red luminescence when exposed to ultra violet (UV) light. XRD and Atomic Force Microscopy of the etched samples were carried out to study the surface of the etched silicon. It is noticed that etching has removed the stress induced atomic layers of silicon at grain boundaries and layer of porous silicon has been formed at the surface of silicon wafer which has higher inter planer distance than the silicon itself. The size of dots observed on the surface of etched silicon is of the order of few $\mathrm{nm}$. The red emission from the surface of etched silicon appears to be due to the energy states induced by quantum confinement.
\end{abstract}

\section{Keywords}

\section{PS, XRD, Electron Confinement}

\section{Introduction}

Silicon, though dominates silicon industry since a long time due to its superior electronic properties but unfortunately till now efficient light-emitting devices have not been achieved owing to its indirect band-gap and poor radiative recombination efficiency [1]. Nowadays, a great deal of interest has arisen in the synthesis and applications of its porous layer due to its luminescent property [2]-[4] and attracted scientists both from fundamental physics point of view as well as its technological applications [5]. Porous silicon because of its unique properties of spatial confinement, dimensionality (large active) and decrease of reflection losses, etc. stimulated many applications in different fields: light emitting diodes, optical sensors, interference filters, wave guides, biomedical applications etc. [6] Lattice expansion and contraction, anisotropy in nano-crystals and high stress in PS/Si interface etc. are the area still open for research. We present here results from XRD analysis and atomic force microscopy. 


\section{Sample}

Chemical etching, with HF-vapors (CHFVE), of phosphorous doped (100)-oriented CZ-grown silicon wafers (one side polished having resistivity $120 \Omega$-cm) was carried out at STP in a vapor reaction chamber, Figure 1. Vapors rising from the surface of the acid pass through the tube, directly interact with the sample in the reaction chamber, exit through outlet and dissolve in water. Immediately after etching samples were rinse with de-ionized distilled water and exposed to ultraviolet light, etched surface was found emitting red.

To study the surface morphology of the etched and controlled samples, Atomic Force Microscopy (AFM) was carried out under a collaborative arrangement with Institute of Semiconductors, Beijing, China. Structural properties of the samples were also studied using XRD technique. The difference in surface morphology and XRD patterns of etched and un-etched samples was examined and results obtained are presented below.

\section{Results and Discussion}

Typical XRD pattern of un-etched samples obtained with JDX-3532 using copper $\mathrm{k} \alpha$ line of wavelength $\lambda=$ $1.5418 \AA$ shown in Figure 2(a), Figure 2(b) depicts four intensity peaks at $2 \theta=67.5,69.35,69.44,69.64$ and 75.63. This pattern was compared with the pattern reported by Jams D Rachwal [8] and Sudesh et al. [7] for (100) silicon single crystal. Jams D Rachwal has shown the scan for XRD reflections from $\mathrm{Cu}(\mathrm{k} \alpha 1) \mathrm{and} \mathrm{Cu}(\mathrm{k} \alpha 2)$, Figure 2(c). After correction, Figure 2(c $\left.c_{1}\right)$, for $\mathrm{Cu}(\mathrm{k} \alpha 2)$, only one single peak at $2 \theta=69.15$ was left reported by other authors also [8]-[11]. The comparison of XRD patterns for our controlled sample \{silicon (100 and reported by Jams D. Rachwal (Figure 2(c $\left.c_{1}\right)$ ) reveals that intensity peak appearing at $2 \theta=75.6$ in XRD pattern of controlled samples is not due to $\mathrm{Cu}(\mathrm{k} \alpha 2)$ line but it may be due to the formation of some unknown species like oxides of silicon on the surface. Similarly intensity peak appearing at $2 \theta=67.5$ is also due to some unknown specie formed on the surface. The small peaks appearing as right and left shoulders may be due to stressed induced planes at the boundaries of the grains.

XRD pattern, Figure 3, for etched samples shows that reflections from (100) planes appear at $2 \theta=69.44$, the same $2 \theta$ values as were noticed for controlled samples. Interestingly reflections at $2 \theta=75.6$ and 67.5 disappeared after etching which confirms that these reflection has nothing to do with structural properties of silicon. The disappearance of shoulder peaks high lights the removal of stress related planes at the boundaries of the

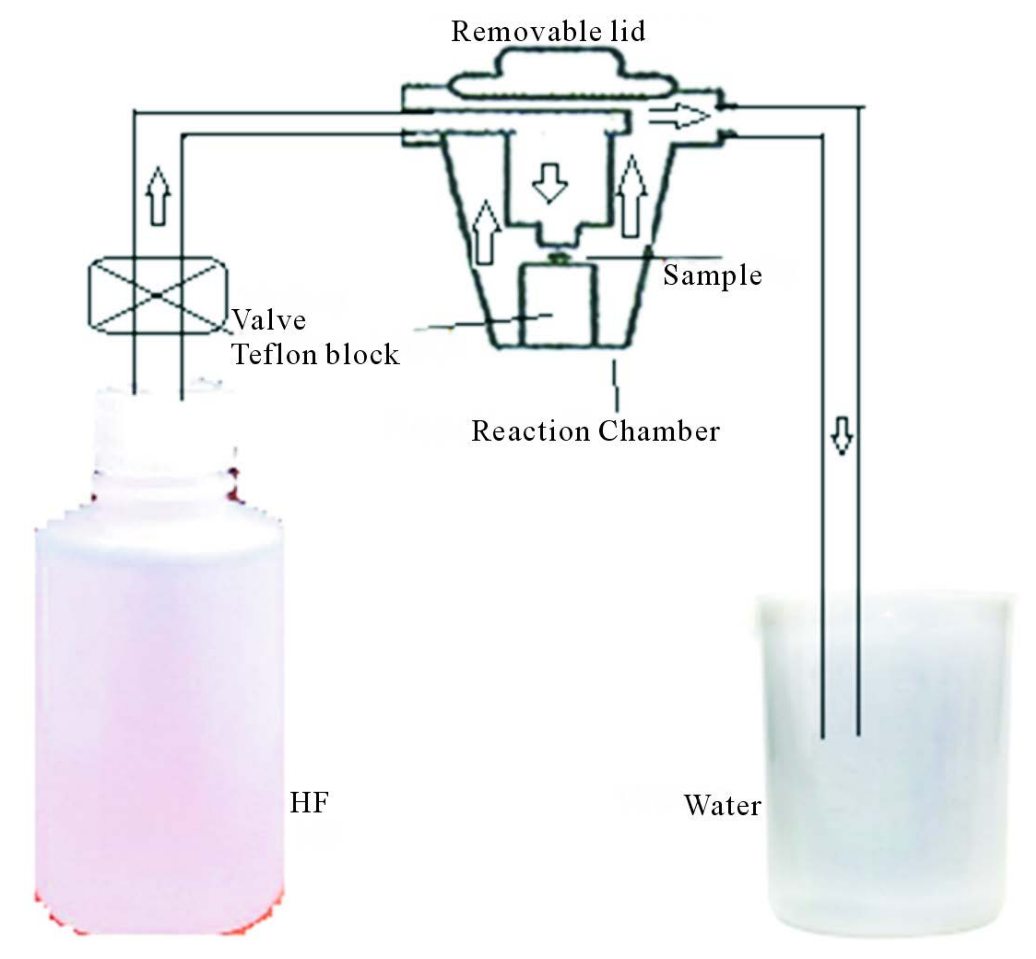

Figure 1. Set up for vapor etching. 


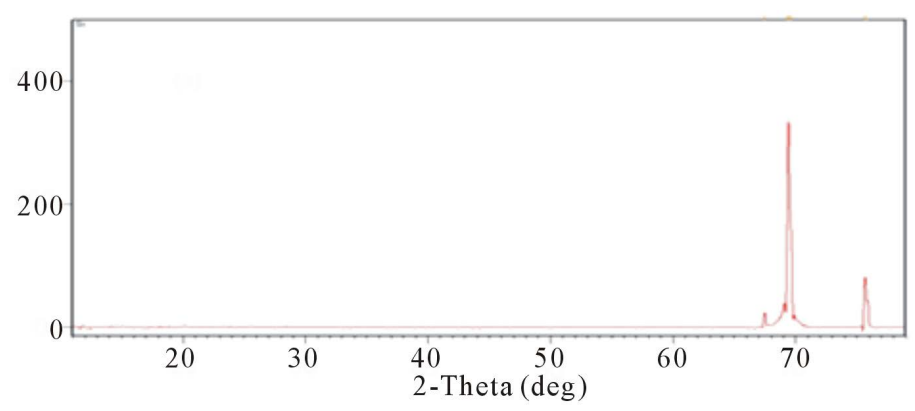

(a)

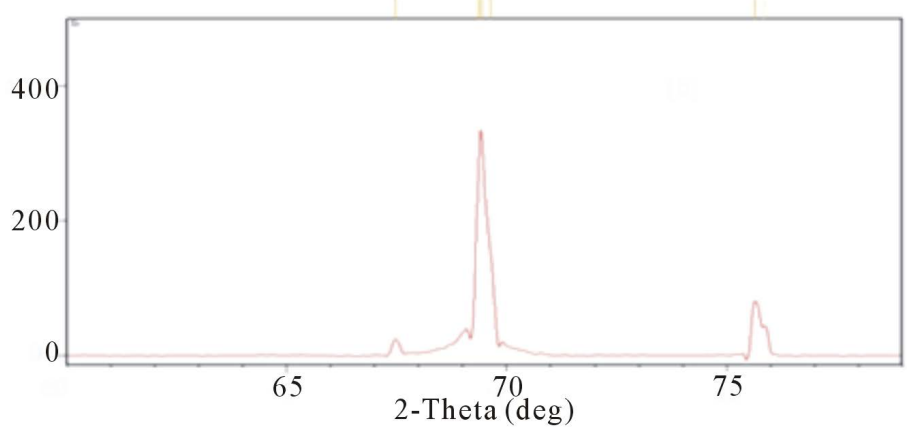

(b)
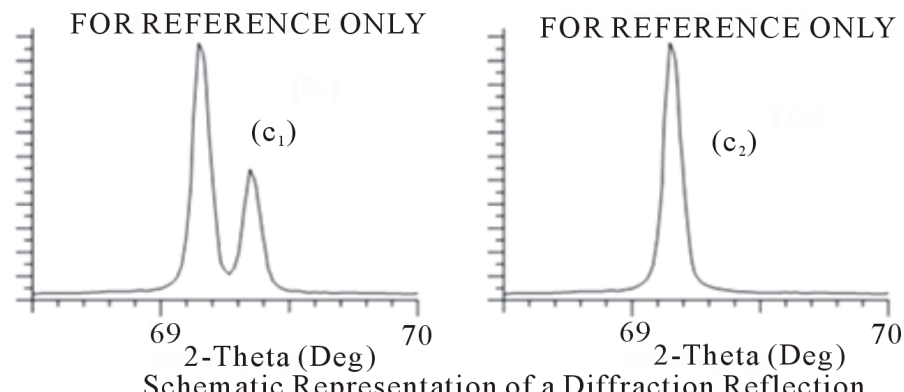

(c)

Figure 2. (a), (b): X-ray diffraction patters of the unetched etched sample; (c): $c_{1}$ before and $c_{2}$ after stripping $\mathrm{Cu}[\mathrm{K} \alpha 2]$ off the raw material [8].

grains. A new intensity peak appears at $2 \theta=29.32$. This new intensity peak can be assigned to porous layer formed at the surface of (100) silicon. Lower value of $2 \theta$ indicates the higher values for inter planer spacing (d values) of atomic layers of porous silicon. The comparison of X-rd pattern with the pattern reported by Aouida et al. [11] for SiOx/Si-containing NH4SiF6 reveals that reflection appearing at $2 \theta=29.32$ in the pattern for our etched samples is closer to the reported (220) reflection. Three dimensional AFM images, Figure 4, of etched silicon surface high-lights the formation of porous layer on the surface of silicon samples. Pyramids like hillocks with etched channels on the slopes. The base dimensions of pyramids at the base are roughly $1 \mu \mathrm{m} \times 1 \mu \mathrm{m}$ and height $1.5 \mu \mathrm{m}$. The dimensions at the top are not clear, however minimum dimension of etched pits are roughly $50 \mathrm{~nm}$. The channel width is roughly $25 \mathrm{~nm}$. Overall pore structure is consisted of more complicated network of etch pits and pyramids. It can be visualized that this porous surface may generates confined emitters of different energies depending on the dimensions of features existing on the surface.

The chemistry that occurs [12] [13] at a silicon surface during vapor etching involves a competition between Si-O, Si-F, and Si-H bond formation. Si-O bonds are chemically attacked by F and significant quantities of Si-O species only form under conditions in which the rate of diffusion of $\mathrm{F}$ to the silicon surface takes place. When the concentration of HF vapors is low, oxidized silicon atoms are generated at the surface too rapidly to 


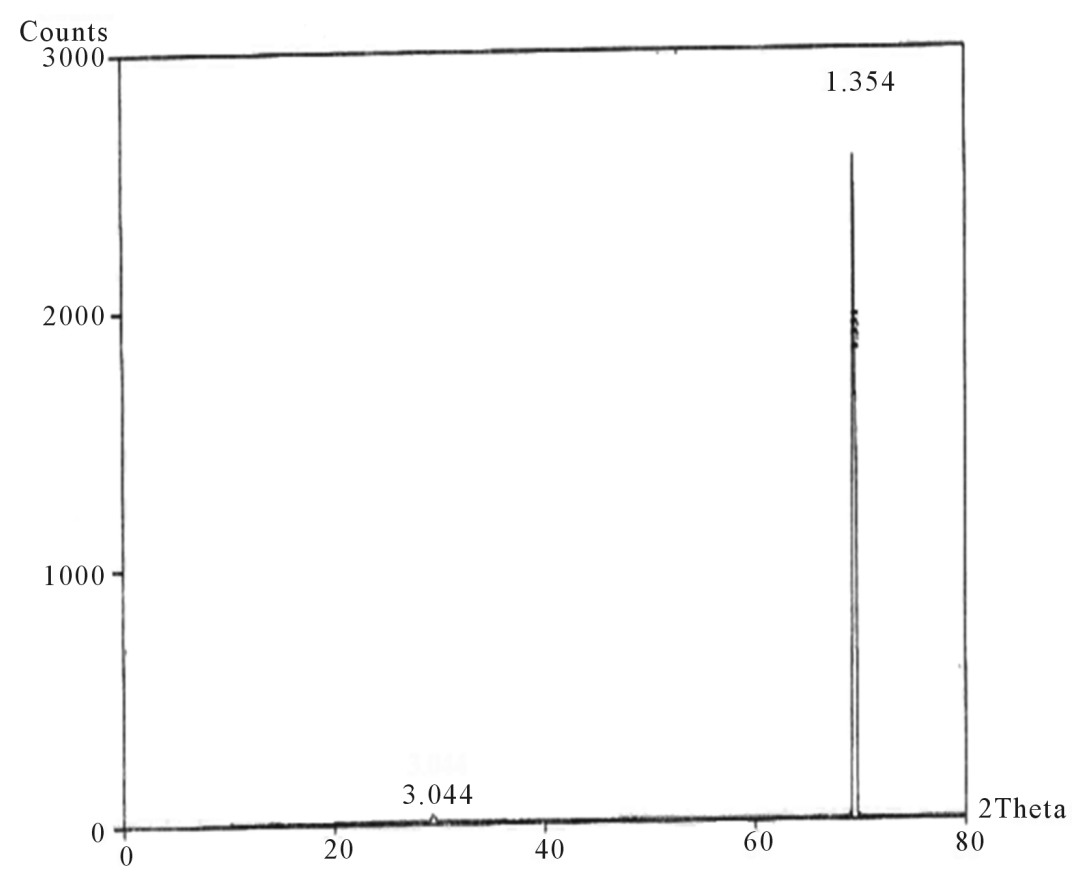

Figure 3. Typical x ray diffraction pattern of etched samples.

be attacked by $\mathrm{F}$ and water molecules take over the simplified mechanism for etching of Silicon surface (fluoride-containing Si surface). The reaction mechanism shifts to Si-O formation and the reaction stoichiometry transitions from 2-electron to 4-electron. The lack of fluoride ions means that the oxide cannot be removed from the surface; this insulating oxide terminates propagation of the pore. The valence band holes are then required to move into the porous silicon matrix to oxidize a $\mathrm{Si}$ atom that is accessible to the fluoride ions instantly formed on the surface. The result is thinning of the pore dimensions close to the porous silicon/crystalline silicon interface. When silicon sample surface is fully covered with HF solution, the oxide dissolves and the surface becomes terminated with $\mathrm{H}$ atoms. This is puzzling if one considers that Si-F is the most thermodynamically stable bond in all of silicon chemistry; the relative strength of bonds increases in the order $\mathrm{Si}-\mathrm{H}<\mathrm{Si}-\mathrm{O}<\mathrm{Si}-\mathrm{F}$. Si-F bonds are highly polarized due to the large electro-negativity of fluorine, and Si-F surface species is much more susceptible to attack by nucleophiles than $\mathrm{Si}-\mathrm{H}$ species. So in a sense, the Si-F bond is to strong; if a fluoride ion attaches to a silicon atom, that atom is rapidly attacked by additional fluoride ions and removed from the surface. The surface silicon takes two paths, depending on the availability of fluoride ions. Reaction follows a path when excess of HF is present (excessive HF diffusion) on the surface and oxidation of silicon occurs on the surface. Reaction follows the other path if HF diffusion is low, water attacks the surface and an insulating oxide is generated and the silicon atoms capped with $\mathrm{H}$ atoms thus predominate on the surface during etch: hydrogen is much less electronegative than fluorine, and a surface with Si-H species is less susceptible to nucleophilic attack. At the end of an $\mathrm{HF}$ etch, porous silicon samples contain primarily $\mathrm{Si}-\mathrm{H}, \mathrm{SiH}_{2}$, and $\mathrm{SiH}_{3}$ surface-groups with minor concentration of O or F related species [14]. Kabbi et al. [6] has shown that Quantum confinement and surface passivation are responsible for the electronic states of the silicon nanocrystallites. A part of porous layer may be related to electron (or even excitons) trapped by Si-O [15] bonds that produce localized levels (energy states) in the band gap of nano-crystallites smaller than few $\mathrm{nm}$.

The comparison of XRD pattern with the pattern reported by Aouida et al. [5] for $\mathrm{SiO}_{\mathrm{X}} / \mathrm{Si}$-containing NH4SiF6 reveals that reflection appearing at $2 \theta=29.32$ in the pattern for our etched samples is closer to the reported for (220) reflection. To understand the role of micro features on the surface of porous silicon, the knowledge of their structural and physical properties is essential. AFM is a versatile non destructive technique, capable of probing single micro surfaces at high resolution, in material science to elucidate surface morphology of the material. The technique gives a new insight into the surface morphology by providing three-dimensional images of the surface with molecular resolution, in real time and with minimal sample preparation. AFM images, shown in Figures 4(a)-(c), revealed a number of complex surfaces of different dimensions/structures appearing 


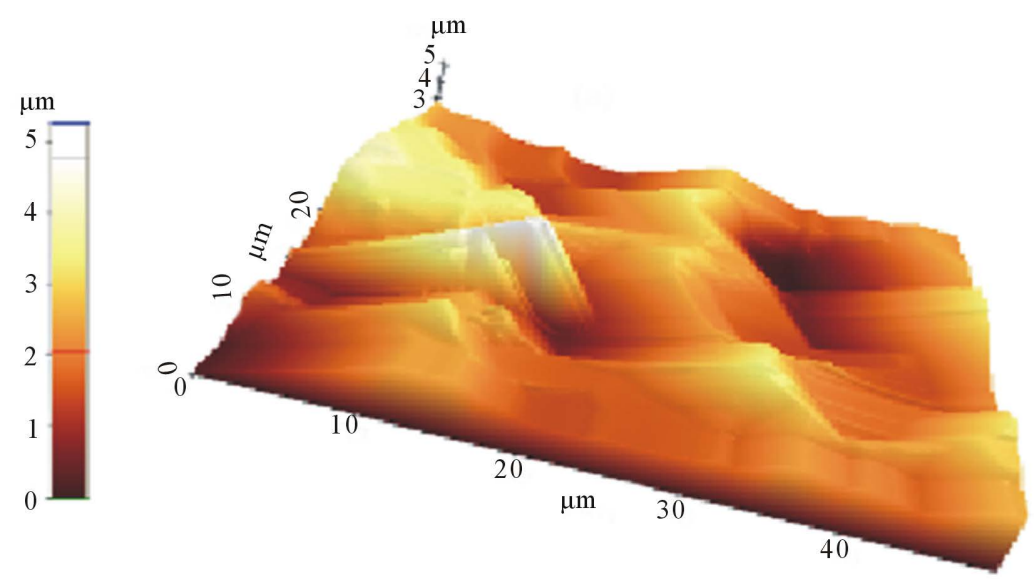

(a)

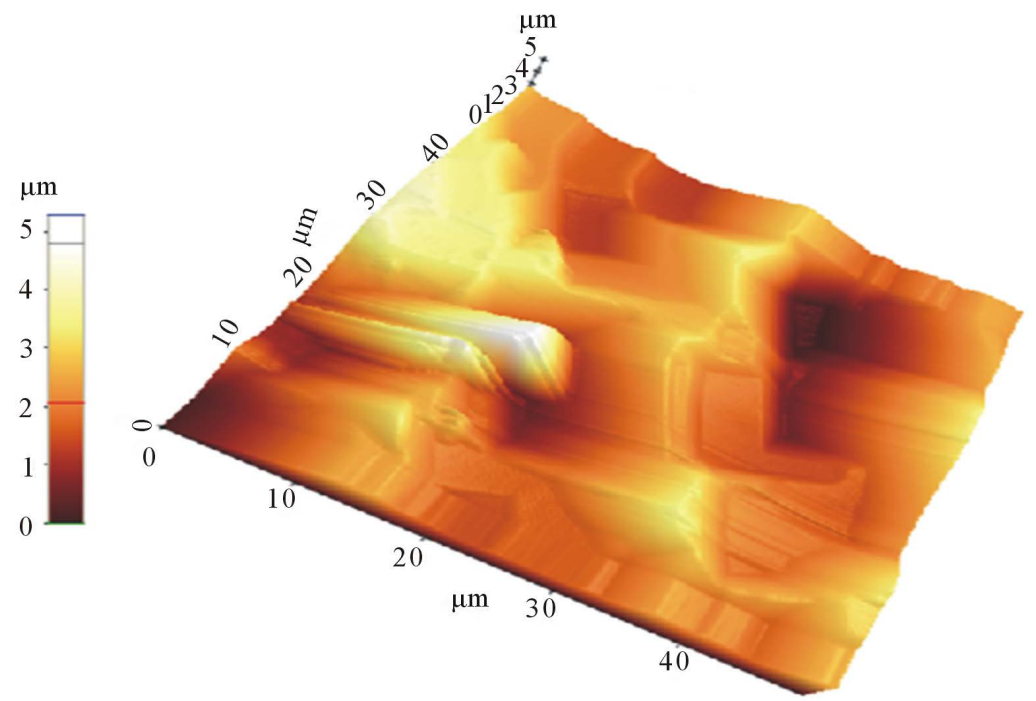

(b)
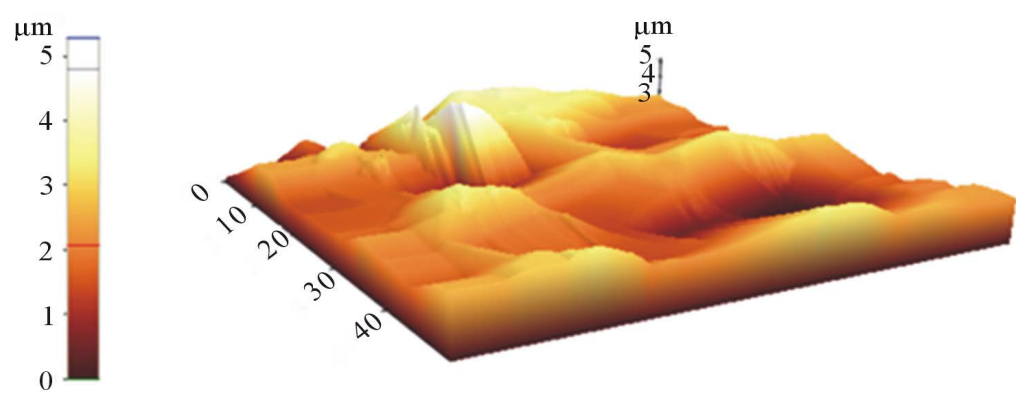

(c)

Figure 4. AFM image $(\mu \mathrm{m})$ of etched siliconscan (a) 2D; (b) in X-; (c) Ydirection.

on the etched surface which are of the order of nm. The dimensionality of the structures and number of complex surfaces suggest the generation of a number of irradiative recombination centers responsible for emission of luminescence due to electron confinement may be of different colors depending on the energy states induced by electron confinement in the material having few atomic dimensions. The emission of a single color is due to dominant formation of microstructures having similar dimensions. Our samples are etched with very slow rate of $\mathrm{HF}$ vapors that reduces the concentration of fluoride ions to interact with surface, which means minimum re- 
moval of oxides from the surface or in other words formation of oxide layer (passivated layer) that may be of the order of Bohr radius. In our opinion red emission is either due to confinement of electrons in nano-crystallites or passivated layer of few atomic dimensions.

\section{Acknowledgements}

Atomic force microscopy of the samples was carried out in Institute of Semiconductors, China, under a collaborative program and other measurements were performed (on payment) at CRL, Peshawar University Pakistan. Etching reaction was performed in Science Laboratory of Denial High School, Rawalpindi.

\section{References}

[1] Kalem, S. and Yavuzcetin, O. (2000) Possibility of Fabricating Light-Emitting Porous Silicon from Gas Phase Etchants. Optics Express, 6, 7-11. http://dx.doi.org/10.1364/OE.6.000007

[2] Vinod, M.P. and Vijayamohanan, K. (1996) Silicon Based Light Emitting Gels. Applied Physics Letters, 68, 81. http://dx.doi.org/10.1063/1.116765

[3] Aouida, S., Saadoum, M., Saad, K.B. and Bessaïs, B. (2006) Phase Transition and Luminescence Properties from Vapor Etched Silicon. Thin Solid Films, 495, 357-360. http://dx.doi.org/10.1016/j.tsf.2005.08.235

[4] Canham, L.T. (1990) Silicon Quantum Wire Array Fabrication by Electrochemical and Chemical Dissolution of Wafers. Applied Physics Letters, 57, 1046. http://dx.doi.org/10.1063/1.103561

[5] Kumar, P., Lemmens, P., Ghosh, M., Ludwi, F. and Schilling, M. (2009) Effect of HF Concentration on Physical and Electronic Properties of Electrochemically Formed Nanoporous Silicon. Journal of Nanomaterials, 18, Article ID: 727957, 7.

[6] Kabbi, H., Miliki, N., Cheynet, M., Saikalay, W., Gibbert, D., Bassïs, B., Yangui, B. and Chari, A. (2006) Structural and Optical Properties of Vapour-Etching Based Porous Silicon. Crystal Research and Technology, 41, 154-162. http://dx.doi.org/10.1002/crat.200510548

[7] Sudesh, T.L., Wijesinghe, L., Li, S.Q., Breese, M.B.H. and Blackwood, D.J. (2009) High Resolution TEM and TripleAxis XRD Investigation into Porous Silicon Formed on Highly Conducting Substrates. Electrochemica Acta, 54, 36713676.

[8] Rachwal, J.D. (2010) Thesis on X-Ray Diffraction Applications in Thin Films and (100) Silicon Substrate Stress Analysis. University of South Florida, Tampa.

[9] Dulov, E.N. and Khripunov, D.M. (2007) Voigt Lineshape Function as a Solution of the Parabolic Partial Differential Equation. Journal of Quantitative Spectroscopy and Radiative Transfer, 107, 428 p.

[10] Parrish, W. and Langford, J.I. (2004) International Tables for Crystallography Volume C: Mathematical, Physical and Chemical Tables. International Tables for Crystallography, 200, 42 p.

[11] Aouida, S., Saadoum, M., Saad, B.K. and Bessaïs, B. (2006) Phase Transition and Luminescence Properties from Vapor Etched Silicon. Thin Solid Films, 495, 357. http://dx.doi.org/10.1016/j.tsf.2005.08.235

[12] Lauerhaas, J.M. and Sailor, M.J. (1993) Chemical Modification of the Photoluminescence Quenching of Porous Silicon. Science, 261, 1567-1568. http://dx.doi.org/10.1126/science.261.5128.1567

[13] Boonekamp, E.P., Kelly, J.J. and Sandag, A. (1994) The Chemical Oxidation of Hydrogen-Terminated Silicon (111) Surfaces in Water Studied in Situ with Fourier Transform Infrared Spectroscopy. Journal of Applied Physics, 75, 8121. http://dx.doi.org/10.1063/1.356510

[14] Mehta, B.R., Sahay, M.K., Malhotra, L.K., Avasthi, D.K. and Soni, R.K. (1996) High Energy Heavy Ion Induced Changes in the Photoluminescence and Chemical Composition of Porous Silicon. Thin Solid Films, 289, 95-98. http://dx.doi.org/10.1016/S0040-6090(96)08937-7

[15] Gole, J.L. and Dixon, D.A. (1998) Potential Role of Silanones in the Photoluminescence-Excitation, Visible Photoluminescence-Emission, and Infrared Spectra of Porous Silicon. Physical Review B, 57, 12002. http://dx.doi.org/10.1103/PhysRevB.57.12002 